\title{
Cooperative Learning and Quality Teaching: Early Career Teachers Striving for Quality
}

\author{
Kate Ferguson-Patrick, The University of Newcastle, NSW, Australia
}

\begin{abstract}
Emphasising the professional development of early career teachers, with an emphasis on pedagogy, is an obvious priority in improving student outcomes. Surprisingly then, in all the rhetoric around mentoring early career teachers (ECTs) this emphasis appears to be missing. This study explores the implications of professional development for ECTs in a particular pedagogical skill, in this case cooperative learning (CL), and the impact of this on the quality of teaching of two early career teachers. An abundance of research literature, over a significant number of years, argues that by focussing on cooperative learning as a pedagogical strategy, students' social and academic outcomes will improve. This paper advocates ECTs expert use of CL to ensure this increase in both social and academic outcomes. The importance of this focus on pedagogy for ECTs as they use CL more in their classrooms is explored by analysing pre and post classroom observations, both in CL and in Quality teaching, as well as semi-structured teacher interviews. These are analysed to investigate teachers' implementation of the cooperative learning strategy, to evaluate their understanding of classroom practice in CL and its impact on the quality of their teaching. The teacher with more years of experience made gains in both cooperative learning and quality teaching demonstrating an emphasis on pedagogy was significant in enhancing her professional accomplishment. The teacher with less experience struggled with other aspects of beginning teaching, such as school context and burnout, which had an effect on the overall quality of her teaching.
\end{abstract}

Keywords: Cooperative Learning, Early Career Teachers, Quality Teaching

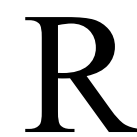

AISING TEACHER QUALITY is a major educational focus for educational bureaucracies. The OECD's recent review (2007), partly funded by Teaching Australia, focused on 'Teaching and Leading for Quality Australian Schools' (Zammit et al., 2007) pointed out that students need to be engaged with content of high intellectual quality while teachers have to use a responsive range of teaching practices to meet the needs of their diverse student population. This particular study investigated a strategy to provide professional development to improve the pedagogy of early career teachers (ECTs) in the area of Cooperative Learning. In this study early career teachers are defined as those in their first three years of teaching. The overall results, of the six teachers in the study, indicated that ECTs were able to further improve their teaching outcomes and confidence when exposed to targeted pedagogical strategies. The study provided support for continued mentoring and support in pedagogy for ECTs in their first few years of teaching. The main focus of this paper is to explore how two of these early career teachers developed their understanding of classroom practice in CL to examine its impact on the quality of their teaching.

Assisting teachers, particularly early career teachers (ECTs), to further develop their teaching skills is important if we are to improve the quality of their teaching. There is widespread consensus that teaching quality is a critical influence on students' learning with the skill of individual teachers being the single largest factor that adds value to student

The International Journal of Learning

Volume 16, Number 12, 2010, http://www.Learning-Journal.com, ISSN 1447-9494

(C) Common Ground, Kate Ferguson-Patrick, All Rights Reserved, Permissions:

cg-support@commongroundpublishing.com 
learning ( Cochran-Smith, 2003; Ingvarson, 2002; Rowe, 2003) and has the most significant impact on student outcomes. Rowe's report on school effectiveness cites many researchers (Darling-Hammond, 1996; Alton-Lee, 2002; Ingvarson, 2002; Cuttance, 2001) who provide the same key message "that quality teachers and their professional development $d o$ make a difference (their emphasis)" (Rowe, 2003, p.24). Additionally the difficulty of retaining early career teachers in the profession has been widely documented. Commencing teachers often experience 'reality shock' (Veenman, 1984) as they juggle the "complex and diverse demands, knowledge bases and contexts for teaching" (Martinez, 2003, p.8). Multiple expectations including "programming, catering for a range of student needs, assessment and reporting and the overriding issues of classroom management" (McCormack, Gore, \& Thomas, 2006, p.96) provide considerable stresses on early teaching experiences (McCormack $\&$ Thomas, 2003). Continuing professional development for all beginning teachers is therefore crucial, not only to support their retention in the teaching profession, but also to ensure their positive impacts on curriculum and pedagogy and student learning (Muijs \& Lindsay, 2007; Talbert \& McLaughlin, 1994).

For teachers, professional development about pedagogy is crucial if student learning is to be improved. However, for the most part, pedagogy is neglected in the induction and professional development of early career teachers (Gore, Williams, \& Ladwig, 2006; Williams, Gore, \& Cooper, 2004). Gore et al (2006) argue that even when teachers are well prepared for teaching in their pre-service preparation, they are still learning to teach, and the general neglect of pedagogy in professional development after these teachers have 'hit the ground running' is a concern.

However, the quality and type of professional development offered is crucial, as inadequate mentoring arrangements occur at present in Australia (Smith \& Ingersoll, 2004). School context, such as the socio-cultural factors and expectations of parents in particular school communities, can affect and challenge early career teachers' prior knowledge and beliefs as well as their self image as teachers (McCormack et al., 2006). Their preparation for teaching is not always sustained by their school cultures (Wang, Odell, \& Schwille, 2008), with beginning teachers often needing to "compromise between their own ideas and recent pedagogical training and the prevailing culture of the school and supervisor" (Khamis, 2000 as cited in McCormack \& Thomas, 2003, p.126). Skaalvik and Skaalvik (2007) assert a strong correlation between teacher self-efficacy and teacher burnout with autonomy being diminished when new teachers have to organise teaching in ways that are in conflict with their own beliefs (Skaalvik \& Skaalvik, 2007). Early support in pedagogy is therefore "critical to the quality of their immediate professional experiences as well as to their longer-term professional learning" (Carter \& Francis, 2001, p. 279). Darling-Hammond puts it strongly, "Well prepared capable teachers have the largest impact on student learning and they need to be treasured and supported" (Darling-Hammond, 2003, p.7). So assisting teachers, particularly early career teachers, to further develop their teaching skills is important if we are to improve student outcomes (Zbar, 2003).

\section{Cooperative Learning as a Pedagogical Tool for Early Career Teachers}

This study has ECTs learning about cooperative learning strategies. It is important to continue to teach teachers about pedagogical strategies in their first years of teaching and CL was selected for use in this case study research into six ECTs. Cooperative learning activities, 
which involve students in heterogeneous (mixed ability) groupings, are designed to allow students to relate learning to the application of big ideas, and to connect their learning through conversations and discussion. The focus on cooperative learning in this study is a result of the extensive research evidence that asserts that Cooperative Learning is an effective strategy in maximising learning outcomes of all students (Gillies, 2003; Johnson \& Johnson, 1994; Johnson, Johnson, \& Smith, 2000; Slavin, 1995, 1996) as well as social skills development (Johnson, Johnson, \& Holubec, 1990; Slavin, 1995, 1996; Stevens \& Slavin, 1995). Cooperative Learning is significant for this project as research has demonstrated it encourages teachers to ask more cognitive and metacognitive questions so that students are required to "provide reasons for their answers, connect their ideas to previous learning, and justify their conclusions" (Gillies, 2007, p.25). Research has also demonstrated students are more likely to be engaged in higher order thinking (King, Staffieri \& Adelgais, 1998) and pose questions to challenge others' perspectives (Palinscar \& Herrenkohl, 2002).

Cooperative tasks, when designed with a clearly focussed goal (ensuring positive interdependence is met by establishing this mutual goal) require students to focus and concentrate on links between concepts/ideas within topics or KLAs throughout the lesson. When teachers divide the main task into smaller sub tasks (task interdependence) then this guarantees the main task cannot be completed without each individual contributing their sub task (this is individual accountability). Students all need to understand each sub task to ensure the main task is completed. When students are given individual tasks (individual accountability) that lead to a group task (positive interdependence) they are required to draw the information together as a whole group which requires higher order thinking (creating, evaluating, analysing) (Anderson, Krathwohl, \& Airasian, 2001). If students are engaged in cooperative learning tasks then they are usually required to actively construct in a higher order way their ideas for goal completion and then in partnership communicate in order to fully understand the complete task. Deep understanding is developed by students constructing explanations and developing reasoning and arguments which require highly developed social skills. Students need to have sustained interactions and students need to scaffold each other's understanding during such explicitly planned cooperative learning lessons. Sustained discussion about concepts and ideas are required when individuals are required to bring their part of the task (due to individual accountability) to the group in order to fulfil the group 'goal' (positive interdependence). Often a variety of viewpoints are put forward in such types of lessons especially when students are encouraged to work on clearly defined tasks that require a main goal but are given choices on how to reach that goal (positive interdependence). They are more likely to be encouraged to address multiple perspectives as a result of exploration of different viewpoints.

The trusting relationships that are built from collaboration are crucial in the development of both the children's emotional as well as academic development, as in a climate which is built upon supportive trust, student learning can thrive (Lovat \& Toomey, 2007). I argue that the focus on solely academic achievement of students is limiting and that Cooperative Learning can address this limitation as it can do much more than just focus on academic achievement. In cooperative learning specific skills of collaboration are taught. Interactions among students are crucial to cooperative learning and the interactions that occur in the groups help to facilitate the learning (Gillies, 2002) with positive relationships occurring as students help each other and enhance thinking. In cooperative groups students are more likely to demonstrate the ability to provide explanations and instructions and develop implicit 
understanding of the needs of other group members than in other types of groups (FergusonPatrick, 2008). The Melbourne Declaration (2008) too states that successful learners should be able "to plan activities independently, collaborate, work in teams and communicate ideas" (Ministerial Council on Education, 2008, p.8) thus emphasising the importance of students learning to collaborate.

Sustained professional learning with an emphasis on pedagogy is important, and a focus on cooperative learning was selected for the focus of the professional learning as an intervention for ECT's in this particularly study. To date there has been no published research that focuses on early career teachers and their use of Cooperative Learning although there has been a great deal of research that advocates the use of Cooperative Learning in schools to improve both social and academic outcomes. The study will also examine broader improvements made in terms of overall pedagogy (using the local New South Wales model of pedagogy's support materials designed for use by teachers in schools, see appendix 1 for brief overview of the NSW model of pedagogy) as classroom observations are analysed both pre and post intervention.

A number of different frameworks for examining good pedagogy have been developed in Australia as a result of the need to raise the quality of teaching and thereupon to improve student outcomes. One of these frameworks, the New South Wales (NSW) Quality Teaching model, was developed by Ladwig and Gore (2003) and grew out of the work of research in the United States on Authentic Pedagogy (Newmann \& Associates., 1996) as well as Queensland's School Reform Longitudinal Study (Queensland School Reform Longitudinal Study, 2001). This framework was used in this study as a guiding model of pedagogy when examining the quality of the teaching of these ECTs. Good pedagogy is defined in my study as being the quality of teaching as defined by the NSW Quality Teaching model (NSW Department of Education and Training, 2003). This model has been developed with the view that good teaching, and in particular the individual teacher, has the most significant impact on student outcomes and the language is also easily accessible to these teachers as it is the framework they have been informed about during their pre-service years.

The NSW model of pedagogy is defined by three dimensions: Intellectual Quality (IQ), Quality Learning Environment (QLE) and Significance (SIG) as well as 18 elements, 6 within each dimension: (see appendix 1). The three dimensions should be present at a high level in every lesson, but not necessarily all of the 18 elements. The model states that the overarching dimension of the pedagogy should be to promote high levels of Intellectual Quality. Teachers should also establish a high Quality Learning Environment and should generate "Significance by connecting students to the intellectual demands of their work" (NSW Department of Education and Training, 2003, p.10). The model is currently being used as a state-wide attempt at pedagogical reform and is being accessed by 2200 NSW DET public schools in Australia as well as being embraced by other school systems (see https://www.det.nsw.edu.au/proflearn/areas/qt/support.htm for more information about the NSW QT model).

\section{Sustained Professional Learning with Action Research}

This paper focuses on early career teachers who focus their professional learning on a specific teaching strategy, cooperative learning, and engage in professional conversations about classroom practice in Cooperative Learning in order to have an overall impact on the quality 
of their teaching. Professional development and teacher induction can play a critical role in enhancing teacher retention and ensuring that beginning teachers do more than survive the early crucial years of teaching. It is important to support teachers in a professional learning community, in collegial professional learning opportunities, as such a collaborative culture (Hargreaves, 2003) "is likely to sustain their commitment, energy and intention to remain in the profession" (Smethern, 2007, p.477). Action research can assist with providing this ongoing support to sustain their commitment. The quality and type of professional development offered is crucial. We know an emphasis on pedagogy is significant in enhancing early career teachers' professional accomplishment and we also need to continue the focus on the importance of quality teaching in the professional learning they receive in their beginning years.

Recent Australian research examined effective professional learning elements for teachers and asserts that it is most effective when teachers can test out their learning within their classroom with both follow-up and feedback being necessary (Victorian Department of Education \& Training, 2005). Professional learning to be most effective should be "collaborative, embedded in teacher practice... school-based and directly relevant to the daily work of teachers" (Department of Education and Training Victoria, 2005, p.6). With this in mind, this present study had a focus on collegial, sustained professional learning sessions conducted throughout the six months study focussing upon both Cooperative Learning and action research which is carried out with the main aim to develop insights and understandings to improve teaching practice (Elliott, 1991), allowing reflection on practice in context .

In this study, professional learning included opportunities for ongoing reflection on Cooperative Learning using teacher reflective journals, as well as action plans related to the implementation of Cooperative Learning in classrooms. Collaborative professional learning opportunities were designed as all teachers shared action plans and classroom implementation concerns. It was designed to be embedded in classroom practice as teachers focussed on implementation of Cooperative Learning throughout the period of the intervention and kept reflective journals and action plans which helped to drive the three professional learning sessions conducted throughout the study. Involvement in action research in classrooms can impact on professional practice and enable informed choices about teaching and learning improvements (Ferguson-Patrick, 2007, 2009). This type of professional learning was therefore designed to provide sustained learning opportunities and allowed individuals to shape their agendas according to their context (Feiman-Nemser, 2001).

\section{Methodology - The Value of Cooperative Learning in Professional Development}

The study focussed on the professional learning on Cooperative Learning as a pedagogical strategy that could help to sustain teachers' enthusiasm early in their careers, as well as develop and improve both their students' academic and social outcomes. The results of this study will be explored in this paper to see what increases in Cooperative Learning were observed after a period of professional learning about the both the strategy CL) and by using reflection and action research. The three professional learning sessions held in this study focussed explicitly on the design of carefully structured lessons with Cooperative Learning key components, as well as how to ensure the essential elements of Cooperative Learning are included in lesson planning and implementation. These sessions focussed on teacher 
understandings of the key components: face to face interaction; positive interdependence; individual accountability; appropriate use of small group skills needed in Cooperative Learning, and student reflective thinking about group functioning. Classroom observations focussed on these key elements as well as the types of grouping practices used; the ways the task was structured to ensure positive interdependence and individual accountability as well as they type of language used by the teacher which encouraged students to cooperative and reflect on their learning.

This paper explores the classroom observations made over a seven month period using both the NSW Quality Teaching framework's coding scale, which has been developed for classroom observations in A Classroom Practice Guide (NSW Department of Education and Training, 2003) as well as the Cooperative Learning coding scale, devised by FergusonPatrick (2006) that has been based on other recent research examining cooperative learning in Australia (Gillies \& Boyle, 2006) as well as most directly based on Johnson and Johnson's (1994) model of Cooperative Learning. These classroom observations have then been graphed to demonstrate each teacher's scores in both Quality Teaching (according to the NSW QTm) and Cooperative Learning (according to the Cooperative Learning scale devised by FergusonPatrick, 2006) across the seven months. Each teacher was observed on three occasions, pre study intervention, in June and early July (end of school term two). Classroom observations in both Quality Teaching and Cooperative Learning were made. During July - September three classroom observations were made in Cooperative Learning and between October and December (final school term four) a final three lesson observations occurred in Quality Teaching and Cooperative Learning.

For the purpose of this paper I will report on two of the teachers in the overall study which consisted of six teachers (using pseudonyms). This case study approach will examine one teacher, Jill, in her third year of teaching, who taught students who were aged 10-13 in a large Independent (non-government) school. Another, Josephine, in her first year of teaching, taught students aged 11-13 in a different large K-12 Independent school. Semi structured interviews were also analysed to determine teachers' understandings and practices in Cooperative Learning after involvement in professional development in Cooperative Learning.

The table (in appendix one) summarises the study's overall methodology and time frame of the professional development in Cooperative Learning. The research study included semi structured interviews, professional learning sessions which included an emphasis on both Cooperative Learning and action research, classroom observations which included video and audio recording of student conversations. A seven month commitment was established with each of the six teachers that included commitment to teaching at least one Cooperative Learning lesson each week, keeping an action research plan and writing a reflective diary.

\section{Results}

Mini case studies of the two teachers described above were explored to evaluate their pre and post understanding of classroom practice in Cooperative Learning and its impact on the quality of their implementation of Cooperative Learning as well as on their overall pedagogy (using the QTm). Semi-structured interviews were also analysed to determine teachers' understandings and practices in Cooperative Learning. 


\section{Jill (Third Year of Teaching)}

The following graphs show the classroom observations of Cooperative Learning (Graph One demonstrating the three periods of observation pre, middle and end of study) and Quality Teaching (Graph Two demonstrating the overall pedagogy both pre and post study) for Jill over the seven month study.

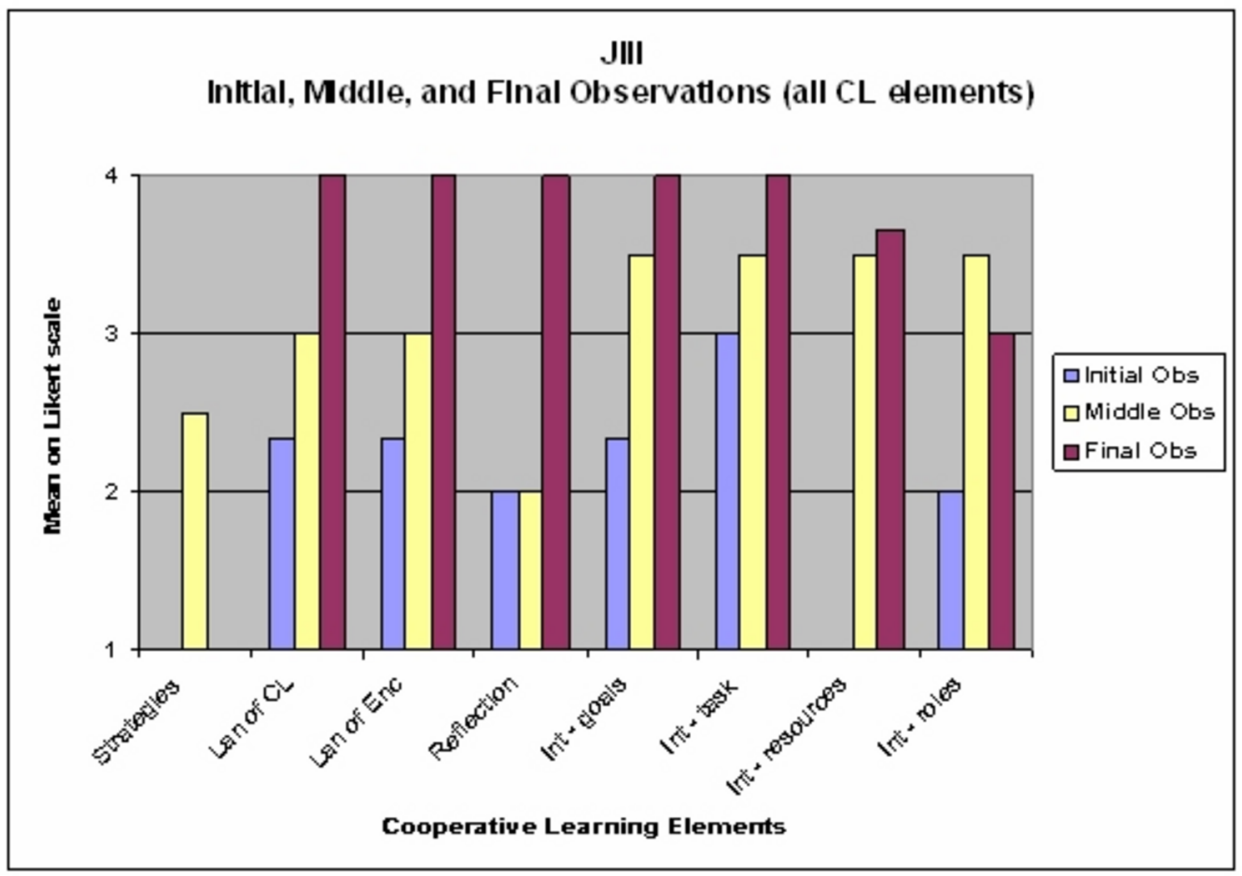

Graph 1: Initial, Middle and Final Cooperative Learning 


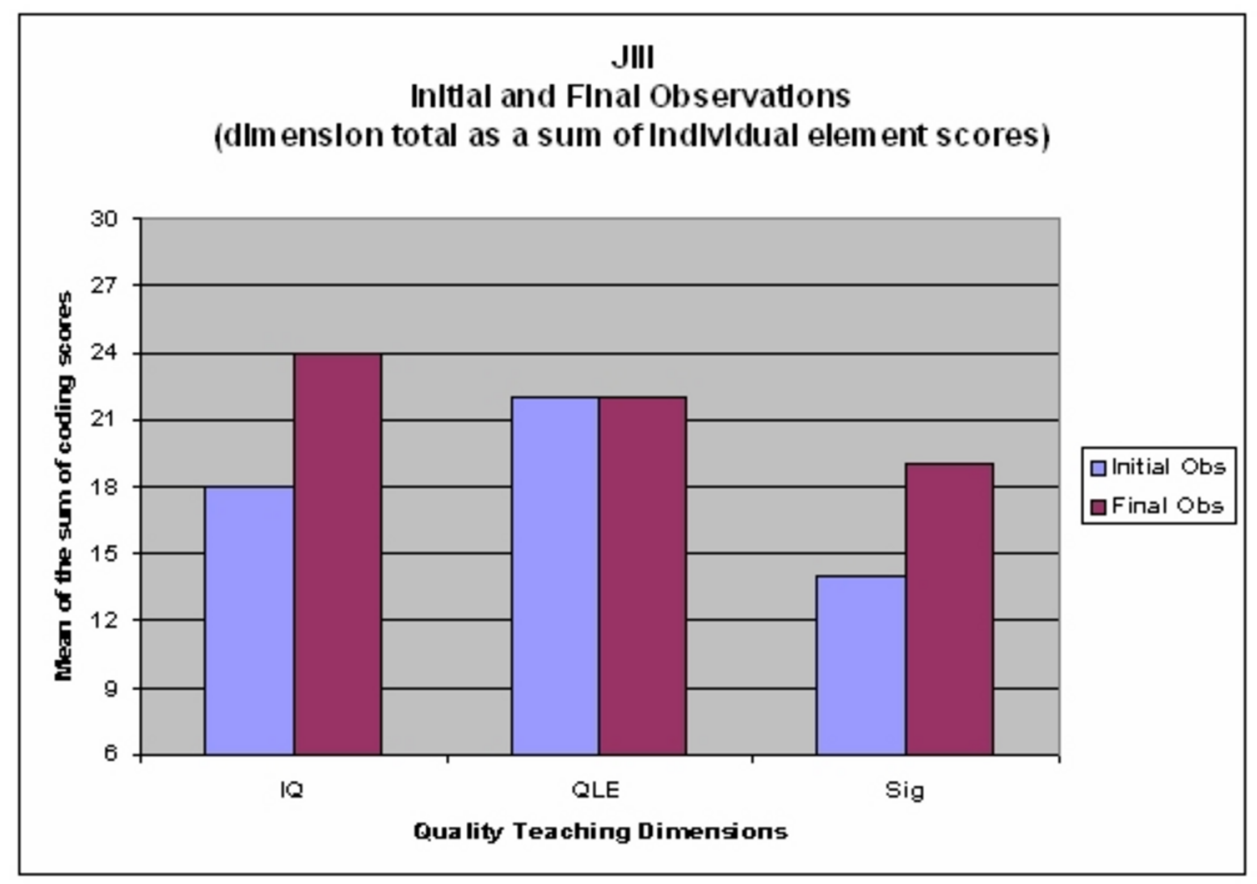

Graph 2: Initial and final obs of Quality Teaching

Final observations demonstrated growth in all areas of cooperative learning. Jill's language use became more explicit as she encouraged her students to use cooperative strategies throughout the lessons and reminded them about their responsibilities within cooperative learning, focusing their attention to individual accountability and positive interdependence. Her ability to build reflective components into the lessons increased as well as her ability to ensure interdependence was established by using goal, task, resource, and role interdependence.

In the final interview, Jill stated that this year had been positive and productive as a result of her use of Cooperative Learning. She acknowledged how being involved in such a project assisted her with revitalising her teaching in this third year out of University;

"It was difficult to find the time for me to seek out more professional development, I was too tired, I had other things to do, whereas this has really kept me on task and it's, yeah my heart's pounding with passion for this again"

The study actually helped her receive a job promotion and she commented on her renewed passion for teaching as a result of the professional development in Cooperative Learning.

"I don't believe I would have got that position had I not done this study as well because I think I've included a lot of what I've learnt in the study in my application and had evidence to back that up. I'm going to be able to have the opportunity to team teach and have professional development days there where I'll hopefully be able to encourage others." 
She spoke in detail about one particular lesson towards the end of the study where she introduced cooperative narrative writing with her class,

" the stories they came up with at the end of the day was (sic) amazing, once they actually got past about three sessions of the group work where their stories they could actually put them together and they could see the building of these narratives and how wonderfully written they were. I found that to be a highlight because it was real high order thinking “

She explained how the whole process was difficult for the children but her high expectations paid off even though at times she doubted herself and this task as being the most appropriate for a Cooperative Learning task,

"no I want to go with it because it was hurting their heads, like I could see their, their faces, they were struggling, they were really struggling. And I thought this is really good. I really wanted to push them that little bit harder and, but at the end like I said the stories that came out of it at the end, they were very creative...they were really keen to finish their stories once they really could see how the jigsaw puzzle was fitting together ...I'm glad I persevered with it"

She also mentions her growth in understanding about the importance of reflection in Cooperative Learning and how this is an area she is also going to continue to work on next year,

"I'll actually follow through a little bit more with the children and find out how they go and how much input they did do. By doing the student evaluations ... by doing that they get to identify what each person is contributing and they also get to take ownership of what 'oh I thought I was actually doing more than that', but however..."

She expressed her understanding of group formation and the importance of these groups being heterogeneous (another key aspect of Cooperative Learning),

"ok who's got the strengths in this group and how can I use these strengths to help this child who doesn't have these strengths but needs to be built up, all these things go through your head at the same time when you're putting them in, then you've got to really be monitoring it..."

and the benefits of Cooperative Learning as they use their interdependence (goal, role, task and /or resource) and individual accountability to produce the best possible learning outcomes,

"with a cooperative group everybody's responsible for the content"

She acknowledged the importance of her role in teaching cooperative learning tasks and the need to ensure she is,

"tapping into the kids' interests you can put them into the cooperative learning, into cooperative learning groups but you need to stimulate, there has to be an interest there to stimulate them and turn the lights on for them and once you've done that they'll just go at a hundred mile an hour so that's fantastic." 
She mentions too the importance of respect that they have built up from day one, and about most of this respect has been a result of setting up a safe, inclusive, environment,

"Respect, respect is a key issue in cooperative learning, you know learning to respect each other as another human being, learning to respect each other's weaknesses and to not to have the put downs and I think that's why my classroom is a safe environment because we've learnt to respect"

Graph 2 indicates that the overall pedagogy demonstrated by the end of the study has improved (according to the QTm and its coding) in Jill's classroom. In terms of Intellectual Quality, which has the highest growth in three dimensions, Jill has ensured all cooperative tasks developed for her students have high intellectual quality. Her students demonstrate deep understanding and there is an obvious concentration on developing tasks with higher order thinking, ensuring students themselves demonstrate higher order thinking skills. The conversations that occur in her classroom as a result of Cooperative Learning see students scaffolding each other. She acknowledged her role in terms of scaffolding their learning during a longer more highly developed cooperative learning task (such as the narrative writing lesson explored previously).

\section{Josephine (First Year of Teaching)}

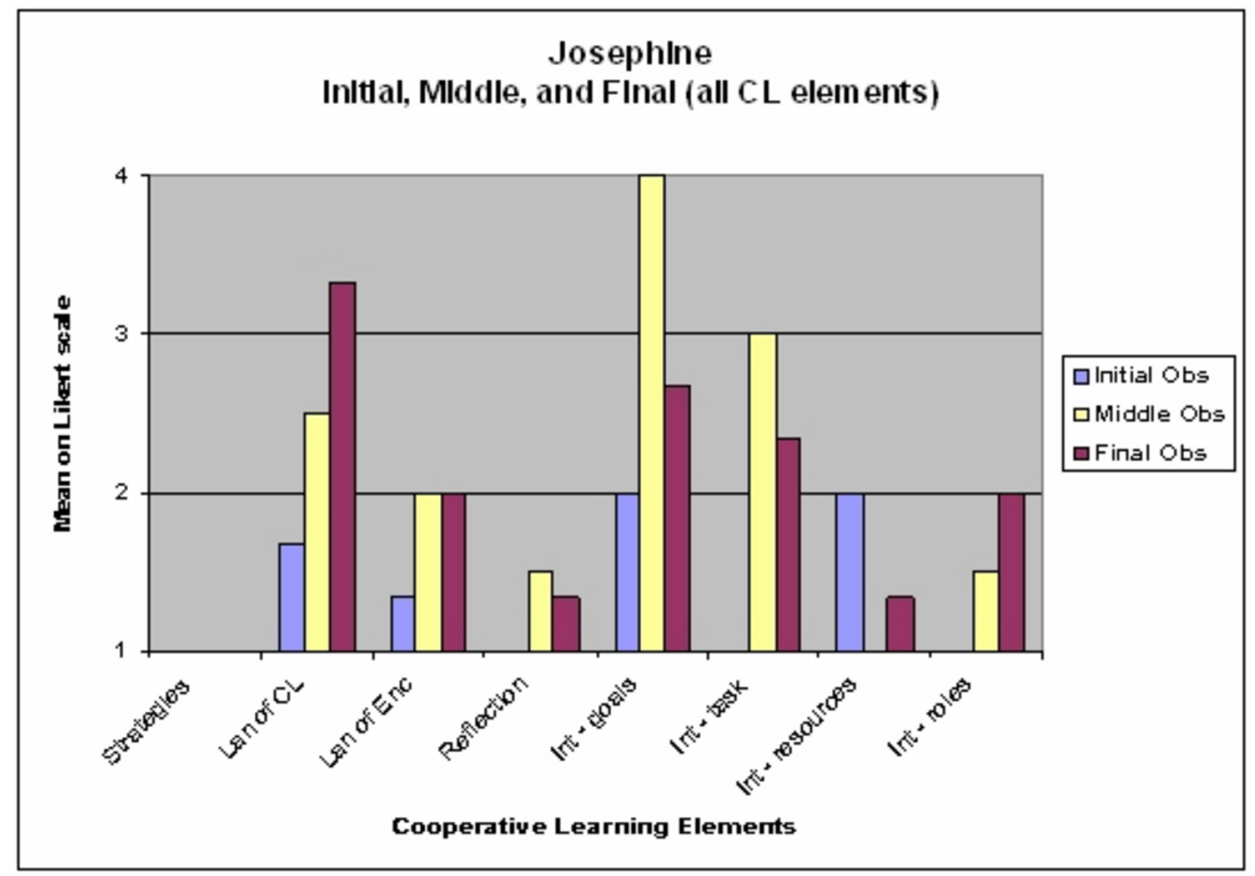

Graph 1: Initial, Middle and Final Cooperative Learning Obs 


\section{Josephlne \\ InItlal and FInal Observations \\ (dimension total as a sum of Indlvidual elem ent scores)}

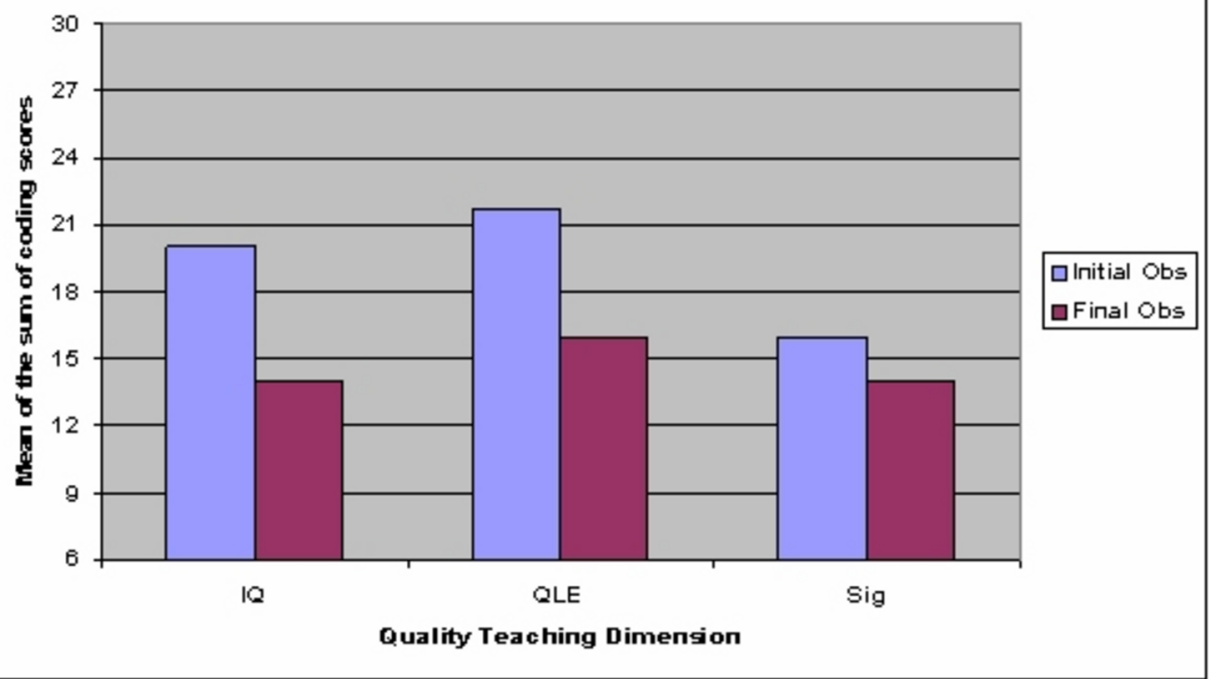

Graph 2: Initial and Final obs of Quality Teaching

Josephine is in her first year of teaching and she particularly struggled with the context of the school and some of the challenges this placed upon her, particularly as she was asked to teach only the Core subjects of English, HSIE (Social Studies) and Maths and not all six primary Key Learning Areas. This did not allow Josephine to really plan an integrated curriculum,

"I just struggled with not being able to make my lessons creative, because I was a core teacher it was English, maths and HSIE and I really wanted to sometimes paint with them or draw with them or take them down to the oval and I really struggled with not, I was like the hard work teacher and I wanted to be more than that, but my position didn't allow me to be and I really struggled with not being able to do the whole big picture... Yeah it was at times very restrictive."

The school focussed heavily on textbooks and individual assessment tasks,

"The amount of textbooks at the school! The amount of assessment tasks, we had 14 assessment tasks to mark for the end of year exams which I thought was absolutely ridiculous."

And this impacted on how many cooperative learning lessons Josephine was able to implement. The use of Cooperative Learning in her classroom did however change in terms of number of lessons implemented, demonstrating her willingness to embark on cooperative group work, 
"The middle of the year they (CL) were almost non-existent up to a few times a week... Oh probably once a fortnight six months ago and now it's a few times a week."

However, at the end of the year she demonstrated signs of teacher burnout. Her assessments in class were completed and it appeared that Josephine did not have the enthusiasm to plan exciting lessons with high intellectual quality at this point in time. It is interesting to note too that her results in classroom observations related to the quality learning environment have decreased and her students appear disengaged too without their teacher planning tasks with high expectations and with high student direction. Her final results in Quality Teaching demonstrate this in Graph 2.

Despite the results in graph 2, graph 1 shows she has made improvements in most areas of Cooperative Learning except for strategies (or tools), which she has not begin to implement as yet, and in terms of establishing positive interdependence in the students' groups with division of resources in order to promote resource interdependence. However she was able to recognise her role in planning for Cooperative Learning,

"A cooperative lesson needs time because I think in the first term it wouldn't be overly successful, you really need to know your students to be able to do it successfully and you've got to plan for it and I know that some days I thought we'd do group work and just walked in and thought it would work and it backfired,.."

She has enjoyed watching the students develop as a result of her use of Cooperative Learning,

"It'll just be that buzz that you like in your room I think if you're cooperative lesson's working it'll be that engaged buzz that they're just talking, talking, talking about being on task and compromising and sorting things out ... it was good to see it was developing."

She understood her role in group development and saw the benefits of students supporting each other,

"When you structure the groups correctly it's like some students scaffold other students' learning, you know like if you sort of put same ability groups I don't think they'd get anywhere but you'll find that some students can pull other students up and support their learning and that sort of thing and it gives them a bit more confidence ... so I found that everyone just scaffolded each other's learning"

She found the process of Cooperative Learning implementation challenging at times, "I really had to push. I really had to push but they were starting to take risks. "but the involvement in the study made an impact on her teaching and planning,

"Well after one of your PDs (professional development sessions) you told us what they need to know to work in groups so I taught them..., it's just so basic but so important so once I taught them how to do it they were a lot better at it."

and on the students' ability to build on each others' ideas, 
"Well they interact and they discuss things and someone will say something and someone will have another comment, someone will question something and they just go deeper and deeper, where as if they read, take notes, no higher order thinking, you're not challenging yourself at all."

\section{Conclusion}

Assisting teachers, particularly early career teachers (ECTs), to further develop their teaching skills is important if we are to improve the quality of their teaching. For teachers, professional development about pedagogy is crucial if student learning is to be improved. We know an emphasis on pedagogy is significant in enhancing early career teachers' professional accomplishment and we also need to continue the focus on the importance of quality teaching in the professional learning they receive in their beginning years. This paper focused on two early career teachers who, after professional learning on a specific teaching strategy, have engaged in professional conversations about classroom practice in Cooperative Learning. One of the ECTs has demonstrated an overall impact on the quality of her teaching. The other in her first year of teaching, has often needed to compromise between her ideas and the culture of the school and shows signs of teacher burnout at the end of her first year. Her autonomy has been challenged as she is forced to organise her teaching in ways that are in conflict with her own previously held beliefs.

Although these are two specific case studies and as such generalisations cannot be made from these findings, the teacher not in her first year of teaching and, therefore not struggling with so many other aspects of beginning teaching, has demonstrated an increase in her overall pedagogy demonstrating too that student learning academic outcomes may have been impacted upon.

The teachers have been able to focus on a strategy that research has shown improves students' social and academic outcomes. It has allowed them to focus their attention on developing their classroom culture in a way that supports collaboration between students. The study, with its focus on reflection and action research, has also developed their enthusiasm for ongoing teacher research which hopefully will be sustained throughout their career. A focus on pedagogy is critically important to enhance all beginning teachers' professional accomplishment and should be ongoing throughout the early years of teaching in order to retain quality teachers in the profession. However we should be mindful that in the first year of teaching other challenges of beginning teaching may need to be mastered before their pedagogical skills can be fully concentrated upon.

The author would like to acknowledge the feedback from members of the School of Education writing groups at the University of Newcastle on an earlier draft of this paper, and that from the anonymous peer reviewers, which helped to get this work published.

\section{References}

Anderson, L. W., Krathwohl, D. R., \& Airasian, P. W. (2001). A taxonomy for learning, teaching, and assessing: a revision of Bloom's taxonomy of educational objectives. New York: Longman.

Carter, M., \& Francis, R. (2001). Mentoring and Beginning Teachers' Workplace Learning. Asia-Pacific Journal of Teacher Education, 29(3), 249-262.

Cochran-Smith, M. (2003). Teaching quality matters. Journal of Teacher Education, 54(2), 95-98. 
Darling-Hammond, L. (2003). Keeping good teachers: Why it matters, what leaders can do. Educational Leadership, 60(8), 6-13.

Department of Education and Training Victoria. (2005). Professional Learning in Effective Schools [Electronic Version]. Curriculum Leadership, 4. Retrieved May 172009.

Elliott, J. (1991). Action Research for Educational Change. PA, USA: University Press.

Feiman-Nemser. (2001). From preparation to practice: Designing a continuum to strengthen and sustain teaching. The Teachers College Record, 103(6), 1013-1055.

Ferguson-Patrick, K. (2007). Writers develop skills through collaboration: an action research approach. Educational Action Reseach, 15(2), 159-180.

Ferguson-Patrick, K. (2008). The values of citizenship in a cooperative classroom: Early career teachers perspectives. The Social Educator, 26(3), 11-18.

Ferguson-Patrick, K. (2009). Writers develop skills through collaboration: an action research approach. In R. A. Schmuck (Ed.), Practical Action Research: a collection of articles (2nd ed.). Thousand Oaks, CA: Corwin Press.

Gillies, R. (2002). The residual effects of cooperative learning experiences: a two year follow-up. The Journal of Educational Research, 96(1), 15-21.

Gillies, R. (2003). Structuring cooperative group work in classrooms. International Journal of Educational Research, 39(1-2), 35-49.

Gillies, R. (2007). High school teachers' discourse and pedagogical practices during cooperative learning. Paper presented at the Australian Association for Research in Education Conference.

Gillies, R., \& Boyle, M. (2006). Ten elementary teachers' discourse and reported pedagogical practices during cooperative learning. The Elementary School Journal, 106(5), 429-451.

Gore, J., Williams, C., \& Ladwig, J. (2006). On the place of pedagogy in the induction of early career teachers. Paper presented at the Australian Association for Research in Education Annual Conference.

Hargreaves, A. (2003). Teaching in the Knowledge Society. Maidenhead: Open University Press.

Ingvarson, L. C. (2002). Building a learning profession. Camberwell, Victoria: Australian Council of Educational Research.

Johnson, D., \& Johnson, R. (1994). Learning Together and Alone: Cooperative, competitive and individualistic learning. Boston, MA: Allyn and Bacon.

Johnson, D., Johnson, R., \& Holubec, E. (1990). Circles of learning : cooperation in the classroom. Alexandria, Va: Association for Supervision and Curriculum Development.

Johnson, D., Johnson, R., \& Smith, K. (2000). Constructive Controversy: the educative power of intellectual conflict. Change, 32(1), 28-38.

Lovat, T., \& Toomey, R. (2007). Values Education and Quality Teaching: the double helix effect. Terrigal: David Barlow Publishing.

Martinez, K. (2003). Mentoring new teachers in new times. Paper presented the Conference of International Council on Education for Teaching and Australian Teacher Education Association, Melbourne.

McCormack, A., Gore, J., \& Thomas, K. (2006). Early Career Teacher Professional Learning. AsiaPacific Journal of Teacher Education, 34(1), 95-113.

McCormack, A., \& Thomas, K. (2003). Is survival enough? Induction experiences of beginning teachers within a New South Wales context. Asia-Pacific Journal of Teacher Education, 31(2), 126-138.

Ministerial Council on Education, E., Training, \& Youth Affairs (MCEETYA). (2008). Melbourne Declaration on Educational Goals for Young Australians. Melbourne: Curriculum Corporation.

Muijs, D., \& Lindsay, G. (2007). Where are we at? An empirical study of levels and methods of evaluating continuing professional development. British Educational research Journal, 34(2), 195-211. 
Newmann, F. M., \& Associates. (1996). Authentic achievement: Restructuring schools for intellectual quality. San Francisco: Jossey-Bass.

NSW Department of Education and Training. (2003). Quality Teaching: A classroom practice guide. Ryde, NSW: Department of Education and Training Professional Support and Curriculum Directorate.

Palinscar, A., \& Herrenkohl, L. (2002). Designing collaboarative contexts. Theory into Practice, 41, 26-35.

Queensland School Reform Longitudinal Study. (2001). The Queensland school reform longitudinal study final report (QSRLS). Brisbane: Education Queensland,.

Rowe, K. (2003). The Importance of Teacher Quality as a Key Determinant of Students' Experiences and Outcomes of Schooling. Paper presented at the ACER Research Conference, Melbourne.

Skaalvik, E., \& Skaalvik, S. (2007). Dimensions of Teacher Self Efficacy and relations with Strain Factors, Perceived Collective Teacher Efficacy, and Teacher Burnout. Journal of Educational Psychology, 99(3), 611-625.

Slavin, R. E. (1995). Cooperative learning : theory, research, and practice (2nd ed.). Boston: Allyn and Bacon.

Slavin, R. E. (1996). Education for all. Exton, PA: Swets \& Zeitlinger Publishers.

Smethern, L. (2007). Retention and intention in teaching careers: will the new generation stay? Teachers and Teaching: Theory and Practice, 13(5), 465-480.

Smith, T., \& Ingersoll, M. (2004). What Are the Effects of Induction and Mentoring on Beginning Teacher Turnover? American Educational Research Journal, 41(3), 681-714.

Stevens, R., \& Slavin, R. E. (1995). Effects of a Cooperative Learning Approach in Reading and Writing on Academically Handicapped and Non-handicapped Students. The Elementary School Journal, 95(3), 241-263.

Talbert, J. E., \& McLaughlin, M. W. (1994). Teacher Professionalism in Local School Contexts American Journal of Education, 102(2), 123-153.

Veenman, S. (1984). Perceived problems of begining teachers. Review of Educational Research, 54(2), 143-178.

Victorian Department of Education \& Training. (2005). Professional Learning in Effective Schools: the seven principles of highly effective professional learning. Melbourne: Office of School Education, Department of Education \& Training.

Wang, J., Odell, S., \& Schwille, S. (2008). Effects of Teacher Induction on Beginner Teachers' Teaching: A Critical Review of the Literature. Journal of Teacher Education, 59(2), 132152.

Williams, C., Gore, J., \& Cooper, S. (2004, December). Imagine if... The impact of quality teaching on the socialisation of early career teachers. Paper presented at the Australian Association for Research in Education, Melbourne.

Zammit, K., Sinclair, C., Cole, B., Singh, M., Costley, D., Brown a' Court, L., et al. (2007). Teaching and leading for quality Australian schools: A review and synthesis of research-based knowledge. Canberra: Teaching Australia.

Zbar, V. (2003). Teaching is the key: Completing the jigsaw. In V. Zbar \& T. Mackay (Eds.), Leading the debate: Selected papers from a decade of the IARTV Seminar Series. Melbourne, Victoria: Incorporated Association of Registered Teachers of Victoria (IARTV). 


\section{Appendix One}

Table 1

\begin{tabular}{|c|c|c|c|c|c|c|c|}
\hline & $\begin{array}{l}\text { Phase } 1 \\
\text { May }\end{array}$ & $\begin{array}{l}\text { Phase } 2 \\
\text { Jun/Jul }\end{array}$ & $\begin{array}{l}\text { Phase } 3 \\
\text { Jul/Aug }\end{array}$ & $\begin{array}{l}\text { Phase } 4 \\
\text { Sept/O } \\
\text { ct }\end{array}$ & $\begin{array}{l}\text { Phase } 5 \\
\text { Oct/Nov }\end{array}$ & $\begin{array}{l}\text { Phase } 6 \\
\text { Nov/Dec }\end{array}$ & $\begin{array}{l}\text { Phase } \\
7 \text { Dec }\end{array}$ \\
\hline First semi structured interview & & & & & & & \\
\hline $\begin{array}{l}\text { Initial Classroom observations - QT } \\
\text { and CL }\end{array}$ & & & & & & & \\
\hline Professional learning session one & & & & & & & \\
\hline Action research plan developed & & & & & & & \\
\hline $\begin{array}{l}\text { Teacher implementation of CL- at least } \\
\text { one lesson per week }\end{array}$ & & & & & & & \\
\hline Classroom Observations - CL & & & & & & & \\
\hline Professional learning session Two & & & & & & & \\
\hline Action research plan developed & & & & & & & \\
\hline $\begin{array}{l}\text { Teacher implementation of } \mathrm{CL} \text { - at least } \\
\text { one lesson per week }\end{array}$ & & & & & & & \\
\hline Professional learning session Three & & & & & & & \\
\hline Action research plan developed & & & & & & & \\
\hline $\begin{array}{l}\text { Teacher implementation of CL- at least } \\
\text { one lesson per week }\end{array}$ & & & & & & & \\
\hline $\begin{array}{l}\text { Final Classroom observations }-\mathrm{QT} \text { and } \\
\mathrm{CL}\end{array}$ & & & & & & & \\
\hline Final semi structured interview & & & & & & & \\
\hline
\end{tabular}

\section{About the Author}

\section{Kate Ferguson-Patrick}

Kate Ferguson-Patrick (B.Ed Hons, MA Children's Literacy and Literature) is Program Convenor BT/BA Primary, a lecturer in Primary education and Assistant Director of Professional Experience Primary at the University of Newcastle, NSW, Australia. She previously taught for 13 years in Primary Schools both in Australia and in the UK. She is presently enrolled in her $\mathrm{PhD}$ and is researching early career teachers' implementation of cooperative learning using an action research approach. She has been involved in the Australian Government Quality Teaching Project as an academic partner supporting the implementation of Mathematics through Action Learning. Her research interests lie in cooperative learning, early career teachers, action research/learning, Studies of Society and Environment, Mathematics and Literacy. 
Copyright of International Journal of Learning is the property of Common Ground Publishing and its content may not be copied or emailed to multiple sites or posted to a listserv without the copyright holder's express written permission. However, users may print, download, or email articles for individual use. 